\title{
A arte de endurecer "miolos moles e cérebros brandos": a racionalidade médico-higiênica e a construção social da infância*
}

\author{
José Gondra
}

Universidade do Estado do Rio de Janeiro, Faculdade de Educação

\section{Inára Garcia}

Universidade do Estado do Rio de Janeiro, Programa de Pós-Graduação em Educação

\section{Introdução}

Ciclos. Etapas. Momentos. Fases. Níveis. Estágios. Períodos. Idades. Estes substantivos, apesar das diferenças que guardam entre si, contêm e auxiliam na construção da idéia de vida segmentada, aspecto que consiste em um ponto de articulação comum entre eles. Remetem e reforçam a tese de que é possível, valendo-se de recursos variados, reconhecer aspectos comuns nas diferentes partes da cronologia da vida. É, portanto, no interior dessa crença que a idéia de infância vem sendo formulada e reproduzida, acoplando-se a ela a criação e reordenação de instituições que passaram a ser estreitamente vinculadas à etapa "mais tenra da vida", como diria Fénelon, no final do século XVII.

* Uma versão deste trabalho foi apresentada no V Seminário do Grupo de Pesquisa Educação, História e Modernidade, ocorrido em abril de 2003 na Universidade Estadual de Campinas (UNICAMP), como resultado parcial da pesquisa do projeto A infância e sua educação, com apoio da CAPES (Brasil) e do ICCTI (Portugal).
Nesse sentido, caberia indagar: o que há de mais homogêneo nessa "primeira idade" da vida? Responder a essa questão supõe estar atento para os critérios empregados na identificação dos seus traços comuns. Ariès, em seu conhecido trabalho História social da criança e da família, chama a atenção para os elementos da fantasia, tradição e exatidão que envolvem a inscrição de um novo ser no mundo civil. Fantasia na escolha do nome. Tradição no sobrenome. E exatidão na definição das idades. Exatidão que convive, segundo ele, com a heterogeneidade dos critérios adotados para descrever/compreender o desenvolvimento humano. Assim, a vida já foi repartida de acordo com o número de planetas, signos do zodíaco, ou mesmo meses do ano. Repartição e terminologia que nos parecem estranhas, mas que à época traduziam noções partilhadas pelos representantes da "ciência", correspondendo igualmente a um sentimento popular e comum da vida (Ariès, 1981, p. 38).

Com a popularização das "idades da vida" indicadas pela iconografia e outras fontes consultadas por Ariès, estas passaram a ser associadas não apenas a etapas biológicas, mas também às funções sociais. 
Para esse autor, a repetição das imagens, pregadas nas paredes ao lado dos calendários, e entre objetos familiares, alimentava a idéia de uma vida dividida em etapas bem delimitadas, correspondendo a modos de atividade, tipos físicos, funções e às modas do vestir. Desse modo, o pesquisador francês assinala que a periodização da vida tinha a mesma fixidez que o ciclo da natureza ou a organização da sociedade (Ariès, 1981, p. 40), a despeito de uma proliferação nas formas de designar as idades. Debate possível de ser percebido na iconografia e nos discursos dos séculos XIVXVIII, prolongando-se para o século XIX, também sendo constituído em problema no interior da comunidade médica e religiosa. Nesse último caso, basta observar o tratado de educação de meninas, de Fénelon, publicado pela primeira vez em 1687, ao lado de suas 48 fábulas e opúsculos pedagógicos, dos diálogos para a educação de um príncipe, dos fragmentos espirituais, das exortações, conversões e sermões, do projeto de comunidade segundo suas idéias e da explicação das máximas dos santos em relação com a vida interior. ${ }^{1}$

Da parte médica, dentre outros manuais utilizados na formação dos futuros doutores, vale assinalar o do professor agregado da Faculdade de Medicina e médico do hospital de Paris, A. Becquerel, intitulado Traité elémentaire d'hygiene privée et publique. ${ }^{2} \mathrm{O}$ Capítulo II, "Des âges", da primeira parte de sua extensa obra, com um total de 893 páginas, tem início com uma reflexão conceitual acerca da idade: "Nós atribuímos, em geral, o nome idades aos diversos períodos de desenvolvimento, de estado estacionário e de decréscimo, que se sucedem durante a evolução

${ }^{1}$ Cabe registrar também a obra Aventuras de Telêmaco, livro escrito com base na experiência de Fénelon como preceptor do filho de Louis XIV. No Brasil, essa obra foi um best-seller durante um século, na virada do XVIII para o XIX, de acordo com estudos de Abreu (2002).

${ }^{2}$ Obra organizada em duas partes: I. Objeto da higiene estudo do homem e o estado de saúde (contendo 10 capítulos); II. Matéria da higiene (com 30 capítulos); e um Apêndice - Higiene aplicada (com 14 capítulos). orgânica do homem desde seu nascimento até sua morte" (1864, p. 9). Acrescenta que toda divisão das idades era necessariamente artificial, na medida em que a evolução completa de um ser humano se fazia sem transição, de uma maneira insensível, sem haver tempo de paradas/interrupções determinadas. Todavia, segundo ele, sempre se procurou estabelecer para as idades uma divisão que relaciona épocas entre as quais haveria uma certa similitude, com base nas relações anatômicas e fisiológicas, separando-se aquelas entre as quais existiria uma dessemelhança muito grande e muito marcada. A partir daí, refere-se a uma classificação antiga que admitia quatro idades (infância, adolescência, idade viril e velhice), de Hallé e Daubeton, para, em seguida, apresentar aquela com a qual efetivamente opera.

Becquerel admite ser a divisão de Hallé uma das primeiras verdadeiramente científicas, repartindo a vida em cinco etapas, cabendo ainda subdivisões e variações, conforme o sexo (Quadro 1).

A classificação de Daubeton, segundo o professor parisiense, desenvolve e regulariza a divisão antiga. Daubeton distribui a vida em seis fases: infância (do nascimento à puberdade), adolescência (até 2025 anos), juventude (25-30/35 anos), idade viril (até 40-45 anos), idade de retorno (45-60/65 anos) e idade da velhice ou caducidade. Na seqüência, apresenta a grade de idades com a qual trabalha, organizando a vida em sete épocas (Quadro 2).

No entanto, ciente da artificialidade da repartição, ${ }^{3}$ conclui essa primeira reflexão acerca das ida-

${ }^{3}$ Poderíamos também dizer, arbitrariedade nessa repartição. Um caso recente em que tal prática se evidencia remete à experiência em curso no Turcomenistão, a mais pobre das antigas repúblicas soviéticas, na Ásia Central, em que o ditador Saparmurad Niyazov, ou Turkmenbashi, decretou a reclassificação das idades dos seus cidadãos. De acordo com esse decreto, as idades da vida passaram a ter a seguinte configuração: 0-13 anos (infância), 1325 anos (adolescência), 25-37 anos (juventude), 37-49 anos (maturidade), 49-62 anos (idade do profeta), 62-73 anos (idade da 
Quadro 1 - Idades da vida, segundo Hallé

\begin{tabular}{|l|l|c|}
\hline \multicolumn{1}{|c|}{ Terminologia } & \multicolumn{1}{c|}{ Descrição } & Idades \\
\hline $1^{\underline{a}}$ infância & & $1-7$ anos \\
\hline $2^{\underline{a}}$ infância - Puerícia & Meninos & $7-15$ anos \\
& Meninas & $7-13$ anos \\
\hline Puberdade ou adolescência & Homens & $15-25$ anos \\
(aptidão para reprodução) & Mulheres & $13-21$ anos \\
\hline \multirow{2}{*}{ Virilidade } & crescente & $25-60$ anos \\
Feminilidade & confirmada & $21-50$ anos \\
\hline & decrescente & 51 anos ou mais \\
\hline Velhice & $1^{\text {a } \text { fase }- \text { Velhice }}$ & $60-70$ anos \\
\hline
\end{tabular}

$\operatorname{des}^{4}$ lembrando que as divisões são feitas apenas para facilitar o estudo e que não se deveria atribuir mais importância do que elas mereciam. Dedica ainda cerca de 60 páginas para caracterizar cada uma das idades de sua cronologia, descrevendo e debatendo a situação de cada uma das etapas, ao mesmo tempo em que prescreve as práticas adequadas para cada nível.

Quadro 2 - Idades da vida, segundo Becquerel

\begin{tabular}{|c|l|l|}
\hline Fases & \multicolumn{1}{|c|}{ Terminologia } & \multicolumn{1}{c|}{ Idades } \\
\hline $1^{\underline{a}}$ & Época do nascimento & Criança recém-nascida \\
\hline $2^{\underline{a}}$ & Primeira infância & Do nascimento até 2 anos \\
\hline $3^{\underline{a}}$ & Segunda infância & $2-12 / 15$ anos \\
\hline $4^{\underline{a}}$ & Adolescência & $12-15$ a $18 / 20$ anos \\
\hline $5^{\underline{a}}$ & Idade adulta & $20-60$ anos \\
\hline $6^{\underline{a}}$ & Velhice & 60 anos até morte \\
\hline $7^{\underline{a}}$ & Época da morte & \\
\hline
\end{tabular}

inspiração), 73-85 anos (idade das barbas brancas), 85-97 anos (velhice) e 97-109 anos (idade de Oguz Khan - monarca ancestral dos povos turcomanos). Cf. Folha de S. Paulo, 15 ago. 2002.

${ }^{4}$ Ao fim de cada seção, o autor apresenta uma bibliografia relativa ao assunto. Para o tema das idades, ele lista: GORDON, Bernard de, De conservatione vitae humanae, a die nativitatis usque ad ultiman horam mortis (vers. 1300). Lipsiae, 1570, in- $12^{\circ}$ BUFFON, De l'homme, de l'enfance, de la puberté, de l'âge viril, de la viellesse et de la mort, em Oeuvres completes; HALLÉ, Encyclopédie. Méth., Art. Ages. T. I, p. 358; DAUBETON, Leçons professes aux écoles normales, t. VIII, p. 314; ESPARRON, Essai sur les âges de l'homme, thèse inaug. Paris, 1803 , in- $8^{\circ}, \mathrm{n}^{\circ} 257$; DENDRIN, De l'influence des âges sur les maladies, these de concours. Paris, 1840; ESTÈVE, Considérations générales sur les âges étudiés etc., thèse inaug. Paris, 1859 , in-4 ${ }^{\circ}, \mathrm{n}^{\circ} 69$.
Esse debate, instalado no chamado velho continente, atravessou o Atlântico, sendo apropriado por professores da Faculdade de Medicina do Rio de Janeiro (FMRJ) e futuros médicos dos trópicos, o que pode ser evidenciado em um conjunto de teses no qual o tema das idades comparece; entre elas, oito tratam diretamente da higiene da infância ou da primeira infância (Quadro 3).

Com exceção da tese de $1840,{ }^{5}$ nas demais Becquerel é constituído em autoridade nas questões de higiene, sendo a reflexão acerca das idades um tema obrigatório em todas elas. A título de exemplo, na primeira tese que desenvolve o ponto referente à higiene da infância, seu autor, o doutor Leitão, inicia a dissertação debatendo o conceito de higiene que, para ele, consiste em uma preocupação que remontava à Antigüidade, em um meio voltado para melhorar a sorte e adoçar a existência dos semelhantes. Para ele, a higiene era um interessante ramo da nobre arte de curar, sendo, sem contradição, de grande merecimento, proporcionando a maior das felicidades, fazendo-nos gozar o melhor dos bens. Ainda nessa linha, assinala que a higiene é uma parte da ciência médica assaz importante, um ramo da moral e, segundo Rousseau, uma virtude, acentuando que feliz era o povo que lhe prestava cultos e que cegamente obedecia as suas leis. Ao fim de seu prefácio (Prefação), alerta que não é seu intento dissertar sobre a higiene em geral, nem o

\footnotetext{
${ }^{5}$ Que pode ser atribuído ao fato de a primeira edição do
} livro do médico parisiense datar de 1851. 
Quadro 3 - Teses da FMRJ que desenvolvem "o ponto" Higiene da infância

\begin{tabular}{|l|l|l|}
\hline \multicolumn{1}{|c|}{ Tese } & \multicolumn{1}{|c|}{ Autor } & Ano \\
\hline Higiene da infância & Antonio Gonsalves d'Araujo Leitão & 1840 \\
\hline Higiene da primeira infância & José Marciano da Silva Pontes & 1863 \\
\hline Higiene da criança do nascimento à queda do cordão umbilical & Francisco Basilio Duque & 1864 \\
\hline Higiene da primeira infância & Ildefonso Archer de Castilho & 1882 \\
\hline Higiene da primeira infância & Nicolao Barbosa da Gama Cerqueira & 1882 \\
\hline Higiene da primeira infância & José Vieira Martins & 1882 \\
\hline Higiene da primeira infância & Severiano Martins de Oliveira Urculu & 1882 \\
\hline Higiene da primeira infância & José Cypriano Nunes Vieira & 1882 \\
\hline
\end{tabular}

curto espaço de uma tese daria campo suficiente para o extenso desenvolvimento de que era suscetível semelhante objeto. Desse modo, procura precisar sua questão: "Nós nos limitamos somente a alguns dos pontos mais importantes relativos á primeira infancia, ${ }^{6}$ que como Mr. Hallé consideramos d'esde o nascimento até a segunda dentição", para, na seqüência, defender sua importância: “A Hygiene d'esta época da nossa vida merece muita consideração; porquanto he ella, que vai plantar os alicerces de huma existência feliz, he ella que fará gozar hum lisongeiro porvir".

Nessa linha de raciocínio, a "existência feliz" e o "lisonjeiro porvir" justificam a periodização da vida $\mathrm{e}$, mais que isso, funcionam como argumento para que a racionalidade médica se debruçasse sobre a "flor da infância", de modo que se construísse um discurso especializado a respeito desse período, do qual se poderia extrair regras para assegurar a continuidade da vida, afastando, com isso, as crianças de práticas rudes, cujos sujeitos por eles responsáveis eram convertidos, pela lógica da ciência, em ignorantes, curiosos e indiscretos. Esse movimento da racionalidade médica, procurando instituir as verdades da ciência ou da razão, ao acompanhar a lógica da natureza, en-

${ }^{6}$ De acordo com a estrutura da tese, organizada em cinco capítulos, os pontos considerados mais importantes são: banhos, vestimenta, aleitamento materno (vantagens, escolha de uma ama, aleitamento artificial, princípio e terminação do aleitamento), $o$ leito do recém-nascido e alimentos. contra-se igualmente atento para os problemas da cultura. Nesse sentido, ao discorrerem sobre o tema da infância, torna-se perceptível a preocupação desses homens com as crianças submetidas a condições desiguais. No caso dos discursos autorizados pela FMRJ, isso pode ser evidenciado no conjunto das oito teses já referidas, como também nas cinco que abordam o ponto das "crianças expostas" e em outro conjunto que trata da higiene dos colégios. ${ }^{7}$ Nessa massa documental, duas representações da infância são forjadas com certa clareza: a da infância rica e a da infância pobre. Representações que, por sua vez, reforçam a hipótese de que, menos que uma descrição biológica ou psicológica, a infância constitui-se em um tempo social e historicamente construído, sensivelmente marcado pelas condições e experiências culturais facultadas a cada criança.

\section{A infância pobre}

O tema da infância pobre no interior do discurso médico comparece acoplado a algumas práticas que se deseja minimizar e, no limite, suprimir. Dentre elas, podemos indicar as práticas de infanticídio ${ }^{8}$ e as de abandono. Neste trabalho fixamo-nos nestas últimas, embora o problema dos "engeitados" se articule em

${ }^{7}$ Uma reflexão acerca da higiene dos colégios pode ser encontrada em Gondra (no prelo).

${ }^{8} \mathrm{Na}$ FMRJ, no século XIX, foram apresentadas 16 teses que abordam a questão do infanticídio. 
um certo grau com o infanticídio, visto que o abandono seria uma forma indireta ou mais branda de os pais, particularmente as mães, livrarem-se dos filhos indesejáveis.

No Brasil, esse tema é associado à criação e ao funcionamento da "roda dos expostos". Na França e no resto da Europa, de modo mais geral, juntamente com as rodas debate-se também a criação dos asilos e das creches. ${ }^{9}$ Inventam-se, assim, lugares específicos e distintos para sujeitos que, mesmo reunindo atributos físicos similares, eram submetidos a experiências culturais bem diferenciadas.

A problemática da infância pobre é tratada na obra de Becquerel no capítulo dedicado às idades. $\mathrm{O}$ tema das crianças abandonadas encontra-se relacionado à questão do registro civil, desdobrando-se no debate referente à legitimidade ou ilegitimidade, que, por sua vez, remete ao sacramento do casamento. $\mathrm{O}$ médico francês, acompanhando os termos da legislação em vigor em seu país, defende a posição de que, nascidos dentro ou fora do casamento, todos deveriam ter sua inscrição na ordem civil. No entanto, lembra a freqüência com que as crianças eram abandonadas nos "hospícios" criados com essa finalidade, ou mesmo em vias públicas, havendo ainda um outro tipo de caso, que era o dos natimortos. Assim, ao reconhecer a prática do abandono, apoiado em estatísticas, afirma que, na França, a cada dois filhos ilegítimos, um era abandonado. Ao tratar mais precisamente do caso das "crianças achadas", pergunta pelas razões do aumento dos "engeitados", apesar da supressão de um grande número de rodas. Na tentativa de explicar a evolução dos algarismos, enumera algumas "razões": a miséria, o crescimento da população industrial, o medo da desonra da parte das jovens seduzidas e o abuso das exposições. O abuso, segundo ele, consistia no seguinte: as mães depositavam seus filhos nos hospícios destinados às crianças, apresentando-se em seguida para alimentá-los, a fim de obter os benefícios da alimentação/amamentação pagos pelos depar-

\footnotetext{
${ }^{9}$ Sobre as rodas no Brasil, ver Marcilio (2001).
}

tamentos de alimentos des enfants trouvés. Preocupado com o crescimento dos algarismos e com esse tipo de prática abusiva, o médico prescreveu três meios para fazer desaparecer os abusos e diminuir o número de abandonados:

$1^{\circ}$ Supressão do segredo na admissão e a necessidade de uma declaração qualquer, meio impossível em certos casos e que, certamente, aumentaria o número de infanticídios.

$2^{\circ} \mathrm{A}$ transferência das crianças e seu envio para outros departamentos diferentes daquele no qual se presume ter nascido e no qual foi depositado.

$3^{\circ}$ A supressão das rodas.

Essa última medida, já em andamento na França, é sustentada pelo contraste estabelecido com os países protestantes que, de acordo com o médico francês, desconheciam a prática do abandono de crianças e onde o infanticídio não era freqüente. Comparação que precisava ser feita com "um pouco de justiça", visto que nos países protestantes, mesmo não havendo "hospícios para as crianças abandonadas", contava-se com os "hospícios de órfãos", que cumpriam funções semelhantes. Um segundo aspecto refere-se à permissão para a realização de pesquisa de paternidade e maternidade, o que concorria para constranger a ilegitimidade, sobretudo se não esquecermos que a quantidade mais numerosa de abandono dizia respeito aos ilegítimos. No entanto, essa questão, até a terceira reedição da obra de Becquerel (1864), ainda não havia sido suficientemente resolvida, havendo ainda quem defendesse a existência de uma roda em cada departamento/bairro.

A apropriação da obra de Becquerel e de outros autores franceses por parte de membros da FMRJ faz com que o debate em torno dos expostos ganhe aqui colorações e tons semelhantes ao modo como a questão era tratada no velho continente. No entanto, as particularidades de um império escravocrata também se manifestam nos estudos travados durante o tempo de formação dos futuros médicos, como consta no se- 
gundo capítulo da tese do doutor Urculu, ${ }^{10}$ que, ao abordar a questão da amamentação por meio da ama, chama a atenção para o exame de três aspectos: a saúde e o estado geral, as qualidades do leite e dos órgãos de lactação da candidata a ama. Ao mesmo tempo, discute a condição social da ama, lembrando que no Brasil havia "amas livres e escravas, sendo estas em número muito mais crescido que aquellas". Embora admita não ser a tese a ocasião "mais azada" para se estudar as condições sociais da ama, não se furta de tratá-la, promovendo uma crítica aguda a respeito da ama escrava. Nesse sentido, indaga:

Sobre que principio racional se funda a lei da escravidão? Em que compendio de estranha moral se lê o artigo, que auctorisa a iníqua practica de nossos deshumanos avoengos, que nos legaram tão execranda herança?

Esta questão, que tem sido ventilada por todas as faces, tem ainda não menor importância quanto á hygiene infantil. (Urculu, 1882, p. 51)

Ainda que numa citação longa, cabe acompanhar os problemas que o médico brasileiro associa à questão da ama escrava:

A tristíssima sorte reservada a estas mães pela força as tem baixado tão miseravelmente que em cada escrava se póde mirar um espelho de máos costumes e hábitos indignos. Effectivamente são elas as que menos respeito guardam pela moral, entre ellas a prostituição é mais torpe, os colloquios mais licenciosos, o decoro e o brio nullos de todo. Mesmo aquellas, que apparentam quando sob as vistas de suas senhoras uma presença mais comedida, confundem-se quasi sempre com o maior número apenas se vêm distantes. Nos passeios, em que podem melhor illudir a vigilância, não raras abandonam as pobres criancinhas para n'um canto pouco acessível á vista e á luz comerciarem por palavras e obras com segundos, quase todas esquecendo o

${ }^{10}$ A respeito da educação das crianças escravas, ver Góes e Florentino (1999); Fonseca (2002) e o dossiê "Negros e a educação", na Revista Brasileira de História da Educação (2002). nobre papel que então representam travam uma conversa immoral e indigna, durante a qual concertam e desconcertam planos, cuja realisação seria largo listrão de lama, que polluiria a cândida veste do pequeno anjo familiar. Não poucas demonstram por gestos, palavras e ameaças a má vontade com que se incumbem do officio de ammas, e chegam até a infligir castigo ao pobre inculpado, dando-lhe beliscões, palmadas, empuxões. (idem, p. 51-52)

Na seqüência, tentando encontrar uma explicação racional para o comportamento que condena, registra ter receio em afirmar que a mãe escrava teria razão em promover tais práticas:

Quem sabe se não é a tyrannica vontade de seu senhor que a obriga a esquecer seu filho legitimo, prival-o de seu cuidados, vel-o rolar descuidosamente pelo chão da cozinha ou nas palhas de um balaio para velar e tratar da criação de um fedelho, que futuramente vai exercer sobre ella própria ou pelo menos sobre seus irmãos de leite a mesma acção que ora seu pai? Quem sabe, se dominada pelos impulsos maternaes que ella não pode conter, não premeditará algum crime que, livrando seu desafortunado filho de um porvir desventuroso, também a delivra actualmente de algum incommodo?

Desejaes que as amas sejam amáveis, carinhosas, cortezes, mas não vos lembraes que não é nesta classe que se encontram aquelles predicados. Os carinhos, que as mulheres escravas dispensam aos seus pequenos senhores, são pela mor parte fingidos pelo medo de incorrerem em castigos severos. Elles se convertem em impropérios e repellões apenas voltam as costas os interessados. (idem, p. 52)

Na crítica às amas escravas, o médico constrói a oportunidade para combater o regime da escravidão e, do mesmo modo, defender o aleitamento natural por parte da mãe, tese muito cara aos higienistas. $\mathrm{Na}$ ótica do doutor Urculu,

O erro gravisssimo de certas senhoras, aliás muitas aptas para por si próprias alleitarem, em entregarem seus filhos á ama cresce de ponto quando essa ama é escrava. Ellas se dedignam de cumprir a augustissima missão de mães 
para não perderem a belleza dos seios, a elegancia do talhe, o torneado dos membros; ellas que não querem ter suas custosas toilletes manchadas por alguma inconveniência do filhinho, que evitam com repugnância a presença de um individuo menos bem trajado, porque a etiqueta... a posição... a nobreza..., não se envergonham de entregal-os aos cuidados de uma pária da sociedade, não coram de ver converter-se em sangue azul de sua familia o leite da escrava! Deshonram-se em estender a mão para darem uma esmola a pobre maltrapilha, mas não pejam de ver conchegado ao peito da escrava seu nobre descendente! Irrisão!...

Do charco immundo do vicio, onde a prepotência arrojou a miseranda escrava, a photographia está bem junta da criancinha. Esta a vê, sente, apalpa, nada mais fácil que imitar o original, e é precisamente no talento da imitação que as crianças são insignes. Não é senão por esta convivência tão intima que nos admiramos de ver crianças tão novas sabendo cousas impossíveis. (Urculu, 1882, p. 52)

Ao concluir, faz uma espécie de exortação em favor da alteração das condições sociais da ama escrava:

Extirpae por meios que vos suggerirem a prudencia e a moral o terrível cancro phagedenico da escravidão, nivelae primeiro as condições sociaes, educae o caracter das novas cidadãs, illuminae-lhes o espirito com o sol da philosophia e confiae-lhes então vossos filhos. Tereis d'ora em diante verdadeiras amas e não impertinentes madrastas. (idem, p. 53)

O registro infância-pobreza-escravidão não esgota a questão da higienização da infância pobre/exposta, visto que, em um outro conjunto de cinco teses, o tema das crianças abandonadas é retomado como questão central (Quadro 4).

Quadro 4 - Teses que abordam o tema da criação dos expostos na Santa Casa da Misericórdia do Rio de Janeiro

\begin{tabular}{|l|l|}
\hline \multicolumn{1}{|c|}{ Autor } & Ano \\
\hline Francisco de Paula Lazaro Gonçalves & 1855 \\
\hline Manoel Velloso Paranhos Pederneira & 1855 \\
\hline Thomaz Baptista Pinto D'Almeida & 1857 \\
\hline Luiz Delfino dos Santos & 1857 \\
\hline José Alexandre Teixeira de Mello & 1859 \\
\hline
\end{tabular}

Infelizes, enjeitados, filhos do abandono, da miséria, da prostituição, da imoralidade, das sombras, da sedução, das fraquezas, do crime, do erro, da censura e do desprezo da opinião pública. Estas e outras representações da criança abandonada podem ser encontradas nesse conjunto de teses apresentadas na FMRJ em meados do século XIX, fabricando uma crença partilhada acerca das crianças expostas nos "hospícios", lugar em que deveriam permanecer até que pudessem se manter por conta própria.

$\mathrm{O}$ discurso médico-higienista, ao privilegiar a questão da criação dos expostos da Santa Casa da Misericórdia do Rio de Janeiro, pauta o debate relativo ao atendimento da criança abandonada no Brasil. O processo de institucionalização é constituído em objeto do interesse médico e a roda passa a funcionar como laboratório no qual deveriam ser observados, comprovados ou mesmo adaptados os resultados das pesquisas na área da higiene, na tentativa de melhorar as condições de atendimento e baixar o índice de mortalidade que, segundo as estatísticas apresentadas, passava dos $80 \%$. Entre os problemas apontados, podemos destacar, na visão higienista, a inadequação do prédio que abrigava as crianças, a má circulação do ar e seu alto índice de contaminação, a temperatura e umidade elevadas, insalubridade, total falta de higiene nas acomodações e roupas das crianças, a dificuldade no controle das amas, características físicas e morais da ama ideal. Ao lado disso, discute-se também a habilitação, a fiscalização e a remuneração das amas, aspectos importantes para elevar a qualidade das mesmas. Todas essas questões eram relevantes, dada a recorrência de epidemias, responsáveis, em parte, pela morte de crianças. Junto a esses trabalhos, os autores citados acrescentam suas experiências, trazendo um estudo detalhado em relação à alimentação dos recém-nascidos, que envolve questões tais como o tipo de aleitamento, análise química dos diversos tipos de leite, diferenças entre o leite humano e dos diferentes animais (vaca, ovelha, cabra e jumenta) e seu emprego na dieta infantil, o aleitamento diretamente do animal e a preocupação com a relação entre a idade do leite e a da criança. Dessa forma, por intermédio de 
citações, mapas ou tabelas, indicavam as formas de diminuir a mortalidade e melhorar as condições dos expostos recolhidos pela roda da Santa Casa da Misericórdia.

No Brasil, a questão dos expostos também é articulada ao debate religioso entre católicos e protestantes. Estes últimos posicionavam-se contrariamente às rodas ou aos "hospícios", pois, segundo eles, a prática do abrigo às crianças enjeitadas colaborava com a miséria, incentivando a imoralidade. Os católicos, no entanto, apelando para a caridade cristã, acreditavam que se deveria garantir o atendimento à criança enjeitada, independentemente de qualquer julgamento humano. Dessa forma, justificavam, à luz da religião, o ato de abandonar na roda como a melhor opção para fazer frente as práticas de infanticídio, uma vez que o acolhimento no "hospício" poderia contribuir para reduzir o percentual da mortalidade infantil.

A roda, na perspectiva da Igreja católica, deveria funcionar como uma espécie de ajuda às famílias que viviam na miséria, as quais, por não terem como criar seus filhos, os abandonavam na "casa da roda", confiando o destino da criança à sociedade de modo geral e à caridade cristã de modo mais preciso. Ao mesmo tempo, o lugar também era reconhecido como a solução mais viável para o caso das moças que se tinham deixado seduzir mediante insistência do amante. Assim, segundo a doutrina cristã, a roda salvava o filho e a mãe, ao esconder da sociedade o fruto do erro, e este, deixado no "hospício", permitiria que a mulher (mãe) solteira reconstruísse sua vida. Nesse sentido, podemos admitir que o expediente da "casa da roda" não se constituía em uma exclusividade da classe social mais baixa, podendo servir também aos interesses da filhas da "boa sociedade", como sugerido na tese de Mello (1859, p. 28-34). Para ele, no Brasil, os expostos surgiam de três classes: a das escravas, das prostitutas e das moças que por um erro, um momento de alucinação, haviam cedido às astúcias de um sedutor.

As cinco dissertações que constam do Quadro 4 também alertam para uma outra modalidade de entrada de expostos na Santa Casa. Era o que eles clas- sificavam de "abusos". Entre estes, estariam os pais que, perante a morte iminente do filho, abandonavam seus corpos moribundos para que fossem enterrados à custa do governo. Havia também, como na França, as mães que deixavam suas crianças para, logo após, apresentarem-se para adotá-las, e com isso receberem um salário para criá-las.

Além desses aspectos, as teses investigadas buscavam na Antigüidade fundamentos filosóficos a fim de ampliar a defesa da necessidade dos hospícios, como se pode perceber no trabalho de Santos (1857):

Era necessário que as nações adquirindo pouco a pouco o sentimento da moral, tivessem dado o seu primeiro gemido à sombra imensa da ignorância, e do envilecimento que os cobria, e proclamado as doutrinas mais puras de uma moral persuasiva e sedutora com a voz de Pythagoras, de Platão, de Aristóteles e de Cicero, para que depois fosse compreendido o Christianismo com todas as suas grandes virtudes. (p. 7-8)

Percurso que, ao desaguar no cristianismo, sedia aí os argumentos em favor da caridade. Procedimento ou estratégia igualmente evidenciável na tese do doutor Manuel Pederneira (1855) que, ao citar a Bíblia (Isaías 49: 15), procura incentivar o acolhimento dos enjeitados: "Se uma mãi chegasse a esquecer seu filho, eu mesmo cuidaria delle e nunca o esqueceria, e aquelle que recolhe uma dessas crianças, tem recolhido a mim mesmo" (p.18). Estas palavras endossam a defesa dos "hospícios", sendo recorrente nas demais dissertações, demonstrando a forma como a religião cristã é abrigada no discurso médico oitocentista.

No que se refere ao movimento de apropriação por parte dos médicos oitocentistas, nas teses analisadas um primeiro olhar aponta para a variedade de nomes, aproximadamente 150, na sua maioria franceses, que colaboraram para fundamentar as idéias, delineando a pauta da ordem médica no século XIX. ${ }^{11}$

${ }^{11}$ No Anexo 1 é apresentada uma amostra de autores que foram referidos, e os modos de sua apropriação. 
Quadro 5 - Apropriações de Becquerel

\begin{tabular}{|c|c|c|c|}
\hline Autor & Obras & Citações & Referência ao autor \\
\hline $\begin{array}{l}\text { Francisco de Paula Lazaro } \\
\text { Gonçalves }\end{array}$ & $\begin{array}{l}\text { Hygiène, } 2^{\mathrm{a}} \text { ed, out./1854 } \\
\text { (p. 35) }\end{array}$ & $\begin{array}{l}\text { - quadro comparativo das três espécies de } \\
\text { leite: vaca, cabra, ovelha (p. } 35)\end{array}$ & \\
\hline Luiz Delfino dos Santos & & - sobre a composição do leite (p. 63) & $\begin{array}{l}\text { - sobre o crescimento das } \\
\text { crianças (p. 32) } \\
\text { - sobre a análise dos diferentes } \\
\text { tipos de leite (p. 59) } \\
\text { - sobre o desenvolvimento das } \\
\text { mamas (p. 61) } \\
\text { - sobre o aleitamento artificial } \\
\text { (p. } 76 \text { ) }\end{array}$ \\
\hline $\begin{array}{l}\text { José Alexandre Teixeira de } \\
\text { Mello }\end{array}$ & $\begin{array}{l}\text { Traité d'hygiène (p. 51) } \\
\text { Analyse du lait (p. 61) } \\
\text { Du lait chez la femme, } 1853 \text { (p. 66) } \\
\text { Annais de hygiène e medicina legal, } \\
2^{\mathrm{a}} \text { série, tomo } 7^{\circ}, \text { Memória de } 1857 \\
\text { (p. 66) }\end{array}$ & $\begin{array}{l}\text { - mapa da composição do leite de } \\
\text { diferentes animais: mulher [sic], jumenta, } \\
\text { vaca, cabra e ovelha (p. } 66 \text { ) } \\
\text { - tabela da importância dos elementos do } \\
\text { leite em cada espécie: mulher, jumenta, } \\
\text { vaca, cabra e ovelha (p. } 67 \text { ) } \\
\text { - classificação comparativa dos leites } \\
\text { segundo o valor de seus elementos (p. 67) }\end{array}$ & $\begin{array}{l}\text { - sobre a composição química } \\
\text { do leite (p. 56) } \\
\text { • sobre a idade do leite (p. 60) }\end{array}$ \\
\hline
\end{tabular}

Diante desse repertório de leituras, podemos avaliar o significado da presença desses autores nos trabalhos investigados, lembrando que a regularidade e a frequiência com que são citados nos leva a considerar o peso da França na formatação do discurso médico da época. Podemos dizer também que os autores lidos voltavam-se principalmente para dois tipos de questões: as de ordem moral, filosófica e religiosa; e as da ordem científica, fruto do progresso das ciências, valendo-se dos resultados das experiências, principalmente da área da higiene, que forneciam, então, sustentação científica para os discursos que circulavam e que eram reproduzidos no âmbito da FMRJ.

Das cinco teses estudadas, uma apresenta o assunto no formato de proposições, motivo pelo qual as fontes utilizadas não se encontram referidas. Nas outras quatro, o tema foi desenvolvido por intermédio de dissertações, e A. Becquerel aparece citado 16 vezes em três delas, com cinco citações, cinco referências à obra e seis referências ao autor, como pode ser conferido no Quadro 5, inscrevendo-o, de modo regular e continuado, na discussão relativa à infância no Brasil do século XIX.

Das cinco obras de Becquerel (Hygiène, Traité d'hygiène, Analyse du lait, Du lait chez la femme e Annais de hygiène e medicina legal) são extraídos os resultados de pesquisas sobre a questão do aleitamento (modalidades e formas), bem como as fontes e análise dos principais componentes e alterações físicoquímicas do leite. Como se pode perceber, ainda que a questão dos expostos tenha sido tratada em sua vasta obra, o uso feito das contribuições do médico francês é bem específico, de acordo com as cinco teses analisadas, referindo-se ao aleitamento, questão que evidentemente preocupa aqueles que pretendiam formular um programa racional/higiênico para cuidar dos expostos, ainda que este consista em apenas uma das questões que afetam o funcionamento desse tipo de instituição. O emprego das reflexões de Becquerel acerca do aleitamento pode ser explicado pelo fato de que este era tido como um dos fatores que mais contribuía para a mortalidade infantil, visto que dizia respeito à alimentação dos recém-nascidos e às condições em que esta se dava na "casa dos expostos", o que ajuda a esclarecer o porquê da busca do apoio ao renomado professor parisiense no intuito de higienizar as práticas de aleitamento a que os expostos eram submetidos. ${ }^{12}$

${ }^{12}$ Sobre a questão da "proteção à infância", cf. também Kuhlmann Jr. (2001) e Gondra (2002). 
O problema da infância pobre coloca-nos mais uma vez diante da questão das idades, tendo em vista que as condições sociais impõem uma agenda diferenciada no que se refere ao tratamento dessa primeira idade, demonstrando que o reconhecimento da existência de semelhanças biofisiológicas são insuficientes para assegurar direitos mínimos e uma existência digna para os semelhantes. A título de exercício, vale observar o tratamento que a higiene - ou parte dela - reservava à infância rica. Outra vez, para desenvolver essa reflexão, nos valeremos de um tratado citado por um médico da FMRJ, em sua tese, em 1875. Trata-se da obra Da educação das meninas, de Fénelon (1852 e 1983), ${ }^{13}$ publicada originalmente em 1687.

\section{A infância rica}

Antes de examinarmos esse manual, consideramos importante acompanhar aspectos da trajetória do seu autor. François de Salignac de La Mothe de Fénelon nasceu no castelo da família de Saint-Mondane, em Périgord, em 6 de agosto de 1651, falecendo em Cambrai, como arcebispo, a 7 de janeiro de 1715, aos 63 anos de idade. Seu pai pertencia à antiga nobreza que foi conduzida quase à ruína em virtude da evolução econômica, do grande número de crianças e da partilha dos bens. Isso marcará o espírito de Fénelon, que então refletirá sobre os meios de restaurar o papel político e a situação econômica da nobreza. Até 12 anos, foi educado em casa. Seu preceptor tinha o gosto pelo latim e pelo grego, tratando logo de lhe ensinar essas línguas para que pudesse se familiarizar com as obras-primas da literatura clássica. Ao completar 12 anos, passou a freqüentar a Universidade de Cahors, onde concluiria os estudos de filosofia, aos quais daria continuidade no Colégio Du Plessis, em Paris. Foi nesse famoso estabelecimento de ensino que se dedicou à teologia e ficou conhecendo o

${ }^{13}$ Trata-se das duas edições dessa obra, com a qual trabalhamos. abade de Noailles, também de família nobre, e ali acabaria alcançando os mais elevados postos na hierarquia eclesiástica francesa. Já se faz perceptível, logo nesta introdução, que os altos escalões da Igreja e da política eram constituídos por gente de elevada linhagem, sendo este o ambiente em que Fénelon se movimentou, ao longo de sua existência.

Do Colégio Du Plessis, Fénelon passou ao seminário de Saint-Sulpice, que à época se encontrava sob a direção de Tronson. Em 1675, o jovem seminarista de 24 anos foi ordenado. Durante os três anos seguintes desempenharia suas funções eclesiásticas, juntamente com os demais sacerdotes daquela paróquia. Cabia-lhe explicar os textos evangélicos ao público, nos domingos e dias santos, participando ativamente das tarefas relativas ao ensino do catecismo. Pretendia, por essa época, partir para o Oriente em missão apostólica, com o propósito de converter ao cristianismo tantos pagãos quantos lhe fosse possível alcançar com o brilho de sua palavra e a amplitude de sua cultura teológica. Mas não seria esse o seu destino, e sim o trabalho nas Nouvelles Catholiques, instituição incumbida de acolher jovens e senhoras recém-convertidas do protestantismo ao catolicismo, a fim de nelas consolidar a boa e ortodoxa doutrina da Igreja. O objetivo era instruir aquelas que se mostrassem dispostas a abandonar a "heresia". A instrução dos "hereges" parece ter sido o principal cuidado de Fénelon, como ele mesmo escreve em 1702.

Era grande a preocupação das lideranças católicas - prelados e leigos - com a salvação das almas que tiveram a infelicidade de se deixar atrair pelas "perigosas" idéias de Lutero. Em 1681, o bispo de Sarlat - também nobre e tio de Fénelon -, renunciou, em favor do sobrinho, ao decanato de Carenas, que rendia de três a quatro mil libras francesas por ano, e o futuro arcebispo deixou por algum tempo as Nouvelles Catholiques, a fim de tomar posse do novo cargo. No entanto, logo retornou à Paris, reassumindo a direção da instituição, posto no qual permaneceria por dez anos.

Graças a sua simplicidade, doçura e caridade, Fénelon obteve considerável sucesso na tarefa, con- 
seguindo converter rapidamente grande número de pessoas. Mas não se iludiu com suas numerosas conquistas, reconhecendo que nem todas eram sinceras, já que, com os protestantes em minoria e postos fora da lei, o catolicismo tornara-se mais confortável ou, no mínimo, mais seguro. Mesmo assim, acrescenta, o resultado de sua missão foi considerado "muito satisfatório". Não escapou, no entanto, de algumas críticas. É que as alas mais radicais da Igreja atacaram seus métodos de conversão e o consideraram "demasiado condescendente com os heréticos".

Nesse ínterim, vagou o bispado de Poitiers. O nome de Fénelon foi indicado e o rei concordou, mas a nomeação não chegou a concretizar-se, segundo foi dito, por causa das intrigas do nobre senhor de Harlay, arcebispo de Paris, que tinha divergências com Bossuet e não via com bons olhos a amizade de Fénelon com o rival. Por essa mesma época, Fénelon sofreu outro revés: o rei negou-lhe a nomeação como co-adjutor do arcebispo de La Rochelle, que o desejava como colaborador.

Pouco depois, em 1689, os bons ventos do sucesso voltaram a soprar em favor do jovem prelado. O duque de Beauvilliers, designado "governador" do jovem duque de Borgonha - neto do rei Luis XIV e herdeiro presuntivo da Coroa-, escolheu Fénelon para o honroso cargo de preceptor do príncipe. Fénelon dedicou-se $\log$ o a trabalhar no intuito de corrigir o comportamento do príncipe por meio de fábulas, que ele próprio ia redigindo. Escreveu, em seguida, Dialogues des morts, no qual punha a dialogar personalidades históricas do passado, empenhadas em (re)avaliar seus próprios atos e posturas. Assim, a preocupação de Fénelon com a educação ou conversão encontra-se visceralmente articulada com sua militância religiosa. São essas vísceras que criam as condições para que redigisse tratados de educação, dispostos a um alcance social mais amplo, como no caso da orientação destinada às mulheres com vistas ao controle das práticas que lhes eram atribuídas, auxiliando-as na condução moral da família, especialmente na educação dos meninos, alvo importante da tarefa feminina.

\section{Da educação das "meninas"}

Em 1687, Fénelon escreveu o livro De l'éducation des filles, primeira obra significativa em sua carreira de escritor e educador. Solicitado pela duquesa de Beauviller para orientá-la na educação de suas filhas, o livro alcançou grande sucesso, tornando-se obra de referência para as famílias da época, bem como texto de consulta para os estudiosos da pedagogia.

Apesar de publicado em 1687, no século XIX ainda circulava no Brasil como um tratado da educação. Sua leitura nos anos oitocentos possibilita pensálo como uma espécie de guia para a formação das crianças da chamada "boa sociedade". ${ }^{14}$ Nela, o autor adverte:

Se a rapariga he nobre ou rica, isenta esta de grosseiros labores; e se algumas horas trabalhar durante o dia será para conformar-se ao commum provérbio. "Que honesto he ás mulheres o trabalharem". Mas isso, as mais das vezes, só será apparente, e ella não se costumará a trabalho assiduo. (Fénelon, 1852, p. 16)

A orientação acerca da escolha e do tratamento dos criados, em capítulo reservado ao recrutamento das aias, tarefa que deveria integrar os deveres da mulher nas situações nas quais ela se encontrava envolvida, mostra, claramente, que essa obra se destinava à educação da mulher rica, da futura mãe de família, a quem caberia "occupações não menos importantes ao publico que as dos homens, visto terem huma casa a dirigir, hum esposo a fazer feliz e filhos a bem educar" (idem, 1852, p. 12).

Considerando o público ao qual esta obra é endereçada, vale refletir acerca do modo como o arcebispo francês contrasta a educação das meninas com a dos meninos. $\mathrm{O}$ autor refere-se ora às meninas, ora aos meninos, crianças, alunos e pessoas jovens, indicando que seu discurso pretendia ter uso e efeito mais

${ }^{14}$ A respeito da formação da "boa sociedade" no Brasil imperial, ver Mattos (2003). 
generalizados. Nesse sentido, podemos entender que, na sua obra, a questão feminina não se apresenta de maneira isolada; apesar de seu nome supor uma restrição, esta não acontece no conteúdo do livro, que termina por expandir a proposta educativa sugerida no título. Essa estratégia decorre, provavelmente, do reconhecimento do autor de que as mulheres, mais precisamente as mães, encontravam-se "predestinadas" a serem educadoras naturais da infância. Desse modo, dependeria delas conhecer as regras para a educação dos dois sexos. Nessa linha, assinala que, ao lado da forma "ordinária" de ensino, doméstica, os meninos também deveriam receber educação no ambiente dos colégios, a fim de formá-los para bem servir à pátria.

Ao iniciar sua reflexão, logo no primeiro capítulo, Fénelon explora as relações entre o ensino das mulheres e a desordem dos homens: ${ }^{15}$

Evidente he, que o mau ensino nas mulheres produz mais mal que o dos homens; attendido que as desordens dos homens derivão quasi sempre da péssima educação que suas mães recebêrão, e das paixões que outras mulheres lhes inspirárão na juventude. (Fénelon, 1852, p. 13)

Para bem desempenhar essa tarefa "natural", era importante que as mães-educadoras conhecessem o espírito proporcionado pela natureza de cada um dos sexos, que dotara homens e mulheres com capacidades diferenciadas, de acordo com a função destinada a cada um na sociedade. No que se refere às características femininas, ele considera que:

As mulheres tem mais fraco e curioso o espiritu que os homens; as mulheres nascêrão para moderados exercicios; porquanto, seu corpo e seu espiritu menos fortes e robustos são que o dos homens; mas em desforra, outorgoulhes a natura industria, aceio e economia para occupa-las

${ }^{15}$ A estrutura em capítulos é uma característica da edição com a qual estamos trabalhando (ver Anexo 2). A primeira versão dessa obra não é dividida em capítulos, consistindo em um texto contínuo. socegadas em suas casas; alem de seu natural mando, alentão ainda o predicado de haverem nascido esmeradas, attentas no miudo, insinuantes e persuasivas. (idem, p. 11)

Acompanhando esse raciocínio, o prelado francês reforça a tese do espírito fraco das mulheres e a inconveniência de "empenha-las nos estudos, nos quaes obstnar-se possão", reafirmando a repartição das funções sociais em virtude do gênero dos indivíduos. Nesse sentido, prega que as mulheres:

Nem governar devem o Estado, abrir guerra ou ingerirem-se no ministerio de sagradas cousas. Não carecem pois de extensos conhecimentos pertencente, á politica, á arte militar, á jurisprudência, á philosophia e a theologia. (idem, p. 8)

Militante da causa da instrução, Fénelon acredita na capacidade e na necessidade das crianças aprenderem desde a mais tenra idade, posição que reforça suas preocupações com a educação na idade dos "miolos moles" ou do "cérebro brando, quente e úmido":

Verdade he que o temperamento do cerebro das crianças lhes da admiravel facilidade para a impressão de todas essas imagens [...]. Moles tem os miolos; porém enduressem diariamente. Quanto ao seu espiritu nada sabe: tudo lhes he novo. Essa cerebral brandura faz que ditos e coisas nella se encrustem facilmente. [...] Essa primeira idade, idade abandonada a mulheres indiscretas e mesmo devassas, he todavia a em que se estampão impressões profundíssimas; e por conseguinte, grande referencia tem ao restante da vida. (idem, p. 25-35)

Com base nisso, prescreve uma pedagogia no sentido de orientar as mães nos cuidados com os meninos, mostrando que, nesse caso, se refere às crianças de maneira geral. Dessa forma, propõe uma metodologia detalhada ao referir-se à alimentação, ao atendimento à curiosidade natural, à atenção às perguntas dos pequeninos, ao cuidado com as respostas e à eficácia dos exemplos na própria conduta dos adultos, recomendando expressamente o uso da literatura re- 
ligiosa que, com suas histórias, "lhes infundirá nobres e indeleveis ideias". ${ }^{16}$ Devemos observar que a presença dos fundamentos da religião constitui-se em traço comum no modelo que constrói para ambos os sexos, o que pode ser atribuído ao seu pertencimento religioso, que termina por se exprimir naquilo que prescreve. Sendo assim, afirma:

Convém os inclinemos mais ás historias santas que a outras, apontando-lhes o quanto são importantes, singulares, maravilhosas, recamadas de nobre vivacidade e naturais pinturas. As da creação, queda d'Adão, diluvio, vocação de Abrahão, sacrificio de Isaac, aventuras de Joseph e fugida de Moisés, são excelentes, pois recreiam os meninos e lhes descortinam a origem da religião christã. (Fénelon, 1852, p. 108)

Afastando-se da generalização/indeterminação das regras, o autor reserva momentos específicos para tratar da educação das meninas. Dentre outros aspectos, aponta para os defeitos que "são falhas communs a seu sexo", entre os quais encontravam-se "a incapacidade de possuírem um firme e regular procedimento..., a facilidade das lagrymas d'encomenda..., as vaidades, que alentam violento desejo de agradar..." (idem, p. 137), propondo, dessa forma, que fossem reprimidas as amizades demasiadamente ternas, os ciumezinhos, excessivos comprimentos, lisonjas, solicitudes, o discurso inútil e os artifícios de que se utilizam para conseguirem o que desejam. Nesse sentido, recomenda:

Conciste a principal prudencia, em falarmos pouco, em desconfiarmos mais de nós que dos outros, mas não em tecer discursos embrulhadores. A rectidão de proceder e o universal crédito de probidade attrahem mais confiança e estima,

${ }^{16}$ Simultaneamente, constrói a idéia da existência de uma literatura perigosa, objeto de interesse das meninas pouco instruídas e inaplicadas, de imaginação sempre errante. Estas davam-se afincadamente à leitura de romances, comédias e narrações de quiméricas aventuras mescladas de amor profano. A boa leitura era, portanto, a literatura sagrada. e por conseguinte, com o andar do tempo, mais vantajens, mesmo temporaes que as vias obliquas. (idem, p. 141)

Sobre a vaidade feminina, altamente combatida, o autor dedica um capítulo do manual para detalhar o que julga como falhas de procedimento: "dhai o aspirarem tanto á formosura e exteriores attractivos, e o apaixonarem-se por adornos; um tocado, huma fita, hum annel de cabelo mais alto ou mais baixo, a escolha d'huma côr, são-lhes importantíssimos negócios" (idem, p. 144), para, logo em seguida, aconselhar às mães que não consentissem nada no exterior das meninas que lhes excedesse a qualidade, reprimindo-lhes severamente as fantasias, a fim de mostrar-lhes a que "perigo nos expomos, e quanto nos volvemos despreziveis acerca das pessoas cordatas, olvidando o que somos" (idem, p. 147).

Fénelon apontou os defeitos e aconselhou regras para o bom ensino - conforme as regras estabelecidas no manual -, indicando também os deveres da mulher que, segundo ele, deveria: encarregar-se do ensino de seu filho até certa idade; das filhas, até que se casassem ou se tornassem religiosas; da conduta dos criados, de seus serviços, das despesas, de modo a tudo fazer econômica e honradamente. Contudo, para que realizassem sua tarefa com perfeição, seria necessário que fossem instruídas. Sendo assim, a mãe de família da elite deveria saber bem sua religião e, apesar de esse manual não conter todo o conhecimento que precisava para orientar os filhos, o autor o considerava suficiente para lhe dar a "intender a extensão dos conhecimentos que urgentes lhes servirão" (idem, p. 151).

No rol de conhecimentos facultados à mulher, o autor sublinha a necessidade de que ela soubesse ler e escrever corretamente, não ignorasse as quatro regras da aritmética e as principais regras da justiça, a fim de poder perceber a diferença entre um testamento e uma doação, bem como as principais regras do direito e dos costumes do país. Aconselha também o conhecimento da história grega ou romana, assim como o da história da pátria e a de outros povos, esclarecendo que essa leitura elevaria a alma a grandes 
sentimentos, contanto que evitassem a vaidade e a afetação. Sugere igualmente a utilidade do latim, de algumas línguas vivas, da poesia e da música. Ao final, advertia a mãe: "Acostume V. Ex. a senhora sua filha a huma judiciosa simplicidade, basta que ella saiba bem a religião para crê-la, e segui-la exactamente na pratica, sem jamais arrogar-se o tom de discorrer de seus augustos mysterios" (idem, p. 161).

Dessa forma, a religião consiste no pano de fundo de todo o manual, pois é perceptível a insistência em reprimir a vaidade e a ostentação, incentivando a riqueza do espírito e a não-riqueza material, atestados da força do discurso religioso. O autor, constituído em autoridade no âmbito da ordem médica para formular um programa para a educação das meninas, propõe um modelo que implica a higienização de práticas privadas, no ambiente da casa, a ser atingida por intermédio da educação das mulheres, e públicas, via reorientação do ensino realizado nos colégios. Essa perspectiva reforça o entrecruzamento entre o discurso médico e o religioso, e dá sentido à apropriação do discurso de Fénelon na tese que discute a higiene dos colégios (Machado, 1875).

\section{Considerações finais}

Pensar a infância implica trabalhar com a idéia de uma vida segmentada, o que nos impõe construir marcos que permitam identificar o começo e o término das diferentes fases, constituindo, assim, um efetivo gradiente das idades, evolutivo e linear. Procedimento que, pela tentativa de se constituir aquilo que seria homogêneo, específico e privativo de cada uma das etapas, termina por repartir a vida de modo mais detalhado do que a clássica idéia do ciclo, a qual se expressa pelo fluxo inevitável do nascimentocrescimento-reprodução-morte, concorrendo também para unificar o que se encontra recoberto em cada uma das supostas idades da vida.

Essa unificação não corresponde às experiências culturais pelas quais passou (e ainda passa) cada sujeito ou grupo social, em diferentes momentos da vida. Com os mesmos 7 anos de idade há, por exemplo, crianças na rua, sem-teto, sem-terra, abrigadas em instituições de caridade, em lares sem pai, sem mãe, sem família nuclear, sem cuidados, submetidas às mais variadas formas de violência e de privação. E há, ao mesmo tempo, crianças bem-alimentadas, bemvestidas, protegidas, atendidas, consumidoras, recobertas de atenção, integrantes e beneficiárias de uma rede de serviços de saúde, educação e lazer. Diferenças que, atualmente, independem, em certo grau, do fato de terem sido concebidas ou não no interior de um casamento formal autorizado pela cerimônia civil-religiosa.

Unificação que pode ser percebida em múltiplos discursos, dentre eles em teses, manuais e guias de higiene do século XIX, ainda que nem todos produzam exatamente o mesmo efeito, cuja disposição não consiste em uma propriedade (ou curiosidade) de um passado mais recuado. Uma rápida e incompleta lista de revistas, programas de televisão, vídeos, filmes, propagandas, músicas, peças de teatro, páginas da internet, brinquedos, jogos, literatura infantil e salas de aula, por exemplo, permite ver que ainda trabalham com a crença de que a infância se constitui em um tempo homogêneo, porque recobre uma mesma cronologia. Basta um exame minimamente atento para detectarmos a representação dominante e universalizante de infância que circula por intermédio desses diferentes veículos, os quais tentam modelar, de forma regular e continuada, o modo como devemos conceber os sujeitos da mais tenra idade, bem como aquilo que com eles devemos praticar.

Enfim, a cronologia da vida e os tipos sociais de infância que procuramos problematizar neste trabalho devem levar em consideração a base, a carga e o tempo de amadurecimento biológico dos sujeitos, não sendo menos necessário reconhecer e admitir que as variantes culturais e a história também definem de modo decisivo as possibilidades surpreendentes da vida e do ser humano.

JOSÉ GONÇALVES GONDRA, doutor em educação pela Universidade de São Paulo, é professor adjunto na Faculdade de Educação da Universidade do Estado do Rio de Janeiro, na área de 
história da educação. Atua também no Programa de Pós-Graduação em Educação dessa universidade. Organizou recentemente, em colaboração, as seguintes publicações: Educação no Brasil: história, cultura e política (Bragança Paulista: EDUSF, 2003); A reorganização do campo educacional: manifestações, manifestos e manifestantes (Rio de Janeiro: 7 Letras, 2003).E-mail: gondra@ uerj.br

INÁRA DE ALMEIDA GARCIA PINTO é mestranda no Programa de Pós-Graduação em Educação da Universidade do Estado do Rio de Janeiro e integrante do Núcleo de Ensino e Pesquisa em História da Educação dessa mesma universidade. Publicações recentes: em colaboração com José Gonçalves Gondra, verbete sobre Eusébio de Queirós no Dicionário dos Educadores no Brasil ( $2^{\text {a }}$ edição revista e ampliada. Rio de Janeiro: Editora da UFRJ, 2002); Recrutamento e profissionalização: ampliando o conceito de formação de professores (II CBHE, Natal, RN, 2002). E-mail: inaragarcia@hotmail.com

\section{Referências bibliográficas}

ABREU, Martha, SCHUELER, Alessandra, (2002). Infância; instrução. In: VAINFAS, Ronaldo (org.). Dicionário do Brasil Imperial. Rio de Janeiro: Objetiva.

ARIÈS, Philippe, (1981). História social da criança e da família. Rio de Janeiro: Guanabara.

BECQUEREL, A., (1864). Traité elementaire d'hygiene privée et publique. $3^{\mathrm{a}}$ ed. com adição e bibliografia feita por Beuagrand. Paris: P. Asselin.

FÉNELON, François de Salignac de la Mothe, (1852). Da educação das meninas. Paris: Typographia de Fillet Fils Ainé. , (1983). De l'éducations des filles. Première version. In: LE BRUN, Jacques. Fénelon - Oeuvres. Paris: Gallimard, p. 1.201-1.230.

FOLHA DE S. PAULO, (2002). Na Ásia, ditador amplia adolescência por decreto e põe seu nome em mês. São Paulo, 15 ago.

FONSECA, Marcus Vinícius, (2002). A educação dos negros: uma nova face do processo de abolição da escravidão no Brasil. Bragança Paulista: EDUSF.
GÓES, José Roberto, FLORENTINO, Manolo, (1999). Crianças escravas, crianças dos escravos. In: PRIORI, Mary Del. História das crianças no Brasil. São Paulo: Contexto, p. 177-191.

GONDRA, José G., (no prelo). Artes de civilizar - medicina, higiene e educação escolar na Corte Imperial. Rio de Janeiro: EDUERJ. , (2002). "Modificar com brandura e prevenir com cautela" - racionalidade médica e higienização da infância. In: FREITAS, Marcos Cezar, KUHLMANN JR., Moysés. Os intelectuais na história da infância. São Paulo: Cortez, p. 289-318.

KUHLMANN JR., Moysés, (2001). Infância e educação infantil. $2^{\mathrm{a}}$ ed. Porto Alegre: Mediação.

LE BRUN, Jacques, (1983). Fénelon - Oeuvres. Paris: Gallimard. MARCILIO, Maria Luiza, (2001). A roda dos expostos e a criança abandonada na história do Brasil (1726-1950). In: FREITAS, Marcos Cezar (org.). História social da infância no Brasil. $3^{\text {a }}$ ed. São Paulo: Cortez, p. 53-80.

MATTOS, Ilmar R., (2003). A construção do império da boa sociedade. In: MAGALDI, Ana Maria, ALVES, Claudia, GONDRA, José (orgs.). Educação no Brasil: história, cultura e política. Bragança Paulista: EDUSF, p. 147-170.

MELLO, José Alexandre Teixeira de, (1859). Que regime será mais conveniente à criação dos expostos da Santa Casa da Misericórdia (...)? Rio de Janeiro: Tipografia Universal.

PEDERNEIRA, Manoel Velloso Paranhos (1855). Que regime será mais conveniente à criação dos expostos da Santa Casa da Misericórdia (...)? Rio de Janeiro: Tipografia Dois de Dezembro de Paula Brito.

REVISTA BRASILEIRA DE HISTÓRIA DA EDUCAÇÃO, (2002). Dossiê "Negros e a educação". Campinas: Editora Autores Associados, $n^{\circ}$ 4, jul.-dez.

SANTOS, Luiz Delfino dos, (1857). Que regime será mais conveniente à criação dos expostos da Santa Casa da Misericórdia (...)? Rio de Janeiro: Tipografia Universal.

URCULU, Severiano Martins de Oliveira, (1882). Higiene da primeira infância. Rio de Janeiro: Tipografia Universal.

Recebido em setembro de 2003 Aprovado em dezembro de 2003 
Anexo 1

Amostra de autores referidos e modos de apropriação

\begin{tabular}{|c|c|c|c|}
\hline Teses & Ano & Autores/obras citados & Tipos de referência \\
\hline $\begin{array}{l}\text { Francisco de Paula } \\
\text { Lazaro Gonçalves }\end{array}$ & 1855 & $\begin{array}{l}\text { Isaías } \\
\text { Matheus } \\
\text { Abade Gaillard } \\
\text { Lamartine } \\
\text { Remacle } \\
\text { Cazeaux } \\
\text { Becquerel } \\
\end{array}$ & $\begin{array}{l}\text { epígrafe } \\
\text { citação da Bíblia } \\
\text { referência ao autor e citação da obra } \\
\text { referência ao autor e citação da obra } \\
\text { referência ao autor e à obra } \\
\text { referência ao autor } \\
\text { referência ao autor e à obra }\end{array}$ \\
\hline $\begin{array}{l}\text { Manoel Velloso } \\
\text { Paranhos Pederneira }\end{array}$ & 1855 & $\begin{array}{l}\text { Bíblia } \\
\text { Remacle } \\
\text { Camper } \\
\text { Caranza }\end{array}$ & $\begin{array}{l}\text { citação } \\
\text { referência ao autor } \\
\text { referência ao autor } \\
\text { referência ao autor }\end{array}$ \\
\hline $\begin{array}{l}\text { Thomaz Baptista } \\
\text { Pinto d'Almeida }\end{array}$ & 1857 & - & - \\
\hline Luiz Delfino dos Santos & 1857 & $\begin{array}{l}\text { Julius Paulus } \\
\text { São Paulo } \\
\text { São Francisco de Paula } \\
\text { Chateaubriand } \\
\text { Platão } \\
\text { Lamartine } \\
\text { Evangelho } \\
\text { Michel Levy } \\
\text { Abade Gaillard } \\
\text { Becquerel } \\
\text { Cazeaux } \\
\text { Donné }\end{array}$ & $\begin{array}{l}\text { epígrafe } \\
\text { citação da obra } \\
\text { referência ao autor } \\
\text { referência ao autor e citação da obra }(2 x) \\
\text { referência ao autor } \\
\text { referência ao autor e epígrafe } \\
\text { citação da obra } \\
\text { referência ao autor ( } 5 x) \text { e citação da obra }(2 x) \\
\text { referência ao autor }(2 x) \text { e citação da obra } \\
\text { referência ao autor }(4 x) \text { e citação da obra } \\
\text { referência ao autor }(9 x) \text { e citação da obra }(5 x) \\
\text { referência ao autor }(15 x) \text { e citação da obra }(8 x)\end{array}$ \\
\hline $\begin{array}{l}\text { José Alexandre } \\
\text { Teixeira de Mello }\end{array}$ & 1859 & $\begin{array}{l}\text { Bíblia } \\
\text { Evangelho } \\
\text { Aristóteles } \\
\text { Platão } \\
\text { Lamartine } \\
\text { Abade Gaillard } \\
\text { Remacle } \\
\text { Becquerel } \\
\text { Cazeaux } \\
\text { Donné } \\
\text { Michel Levy }\end{array}$ & $\begin{array}{l}\text { citação } \\
\text { citação } \\
\text { citação da obra } \\
\text { citação da obra } \\
\text { referência ao autor }(2 x) \\
\text { citada a obra } \\
\text { referência ao autor e citação da obra } \\
\text { referência ao autor }(2 x) \text { e citação da obra }(7 x) \\
\text { referência ao autor }(3 x) \text { e citação da obra }(2 x) \\
\text { referência ao autor }(7 x) \\
\text { referência ao autor }(7 x) \text { e citação da obra }\end{array}$ \\
\hline
\end{tabular}

Anexo 2

Fénelon - Da educação das meninas (1852) - Taboa dos capítulos

\begin{tabular}{|l|l|r|}
\hline Capítulos & \multicolumn{1}{|c|}{ Títulos } & Páginas \\
\hline I & Importancia da educação das meninas & 5 \\
\hline II & Inconvenientes das educações ordinarias & 15 \\
\hline III & Quais são as bases primeiras do ensino & 44 \\
\hline IV & Imitação a temer & 48 \\
\hline VI & Instruç̧̃es indirectas. Não devemos constranger os meninos & 104 \\
\hline VII & Uso das historias para os meninos & 115 \\
\hline VIII & Modos de fazer entrar no espiritu dos meninos os elementos da religião & 127 \\
\hline IX & Instrucções acerca do Decalogo, sacramentos e oração & 137 \\
\hline X & Observações acerca de alguns defeitos das meninas & 144 \\
\hline XI & Instruções das mulheres acerca de seus deveres & 148 \\
\hline XII & Continuação das obrigações das mulheres & 152 \\
\hline XIII & Das aias & 157 \\
\hline XIV & Conselhos a huma senhora acerca da educação de suas filhas & 160 \\
\hline
\end{tabular}


José Gondra e Inára Garcia

$A$ arte de endurecer "miolos moles e cérebros brandos": a racionalidade médico-higiênica e a construção social da infância

Pensar a infância implica trabalhar com a idéia de uma vida segmentada, construir marcos de começo e término das diferentes fases, num gradiente de idades evolutivo e linear. Assim, a tentativa de especificar essas etapas termina por repartir a vida de forma detalhada, além de unificar o que se encontra recoberto em cada uma das supostas idades da vida. Unificação que não é propriedade de um passado mais recuado, pois persiste na atualidade a crença em uma infância homogênea e cronologicamente repartida. Dessa forma, a cronologia da vida, problematizada nesse trabalho, considera tanto a base, a carga e o tempo de amadurecimento biológico dos sujeitos, como as variantes culturais e a história, que também definem, de forma decisiva, as possibilidades surpreendentes do ser humano.

Palavras-chave: educação; infância; higiene

The art of hardening "soft minds and tender brains": a medicalhygienic rationality and the social construction of childhood

A reflection on childhood implies working with the idea of a segmented life, establishing initial and final limits for the different phases, in an evolving linear age scale. Thus, the attempt to specify such stages ends by dividing life up into multiple segments, in addition to unifying what remains hidden in each of the supposed ages of life. Unification is not the property of a more distant past, as the belief in a homogeneously and chronologically divided childhood persists up until now. In this way, the chronology of life discussed in this article, considers not only the base, load and time of people's biological maturation, but also the cultural differences and the history that define, in a decisive way, the surprising possibilities of the human being.

Key-words: education; childhood; hygiene

João Batista Martins

Contribuições epistemológicas da abordagem multirreferencial para a compreensão dos fenômenos educacionais

Apresenta as contribuições da abordagem multirreferencial para a compreensão dos fenômenos educacionais enfatizando os aspectos epistemológicos que ela contempla. Nesse sentido discute-se o momento histórico em que a noção de multirreferencialidade é estruturada e, em seguida, alguns conceitos utilizados que recolocam algumas questões epistemológicas inerentes ao processo de conhecimento acerca dos fenômenos sociais e, mais especificamente, aqueles concernentes à educação.

Palavras-chave: multirreferencialidade; educação; epistemologia

Epistemological contributions of the multi-referential approach to the understanding of educational phenomena

Presents the contributions of the multireferential approach to the understanding of educational phenomena emphasising the epistemological aspects. To this end, we discuss the historical moment in which the notion of multi-referentiality is structured as well as some of the concepts used to re-situate the epistemological questions inherent to the knowledge building process on social phenomena and, more specifically, those related to education.

Key-words: multi-referentiality; education; epistemology
Martha Marandino

Transposição ou recontextualização? Sobre a produção de saberes na educação em museus de ciências A transformação do conhecimento científico com fins de ensino e divulgação se constitui como espaço-tempo de produção de novos saberes. Com base nesse pressuposto, esse trabalho estudou o processo de transposição didática/museográfica e de recontextualização nos espaços de museus de ciências, procurando entender os mecanismos de constituição do discurso expresso nas exposições que abordam temáticas biológicas. Para isso, tomou-se por base referenciais teóricos advindos principalmente do campo da educação e da museologia que pudessem auxiliar na compreensão das especificidades que os museus impõem a esse processo de produção. Esse texto discute particularmente o processo de construção do referencial teórico utilizado na pesquisa, já que de uma escolha fundamentada no conceito de transposição didática/ museográfica, optou-se - com base nas críticas e nos limites do uso desse conceito - por assumir como principal suporte teórico o conceito de recontextualização. Com base nessa discussão foi intenção levantar limites e possibilidades do uso do conceito de transposição didática e analisar os desafios de trabalhar com o conceito de recontextualização para o estudo dos processos educativos nos espaços de museus de ciências.

Palavras-chave: transposição didática; recontextualização; transposição museográfica; educação em museus

Transposition or recontextualisation? On the production of knowledge in education in science museums The transformation of scientific knowledge for teaching or public communication purposes, constitutes a 